D.O.I.: $10.3895 / \mathrm{S} 1808-04482007000300008$

\title{
AVALIAÇÃO QUALITATIVA DAS DECISÕES DO CONSELHO DE ADMINISTRAÇÃO: O CASO DE UMA INSTITUIÇÃO FINANCEIRA
}

\section{QUALITATIVE EVALUATION OF THE DECISIONS OF CONCIL OF ADMINISTRATION: THE CASE OF A FINANCIAL INSTITUTION}

\author{
Mário Domingues Ferreira ${ }^{1}$; Osvaldo Luiz Gonçalves Quelhas ${ }^{2}$ \\ ${ }^{1}$ Universidade Federal Fluminense - Niterói - Brasil mariodomingues@hotmail.com \\ ${ }^{2}$ Universidade Federal Fluminense - Niterói - Brasil quelhas@latec.uff.br
}

\begin{abstract}
Resumo
Este paper apresenta uma visão teórica ampliada acerca das principais abordagens conceituais que tratam de governança corporativa, balanced scorecard, processo decisório e sustentabilidade, como forma de analisar as decisões do Conselho de Administração de um dos maiores conglomerados financeiros do país. O objetivo principal do estudo foi investigar as deliberações daquele colegiado, buscando avaliar os critérios observados no processo decisório, verificando a pertinência destes com a estratégia definida no modelo de gestão, nas políticas técnicas e nos códigos de melhores práticas de governança corporativa recomendadas pela literatura e pelos órgãos reguladores.

Palavras-chave: Governança corporativa, balanced scorecard, processo decisório, sustentabilidade.
\end{abstract}

\section{Introdução}

Um dos problemas mais complexos para o desenvolvimento sustentável de qualquer organização refere-se à origem de recursos para o financiamento das suas atividades. Cantidiano e Correa (2004) afirmam que a experiência do autofinanciamento, em muitos casos, mostra-se inadequada e excessivamente onerosa e apontam que uma das razões para o fracasso da maioria das empresas, em curto espaço de tempo, deve-se ao financiamento da atividade com poupança própria. Com tal motivação, no âmbito do financiamento empresarial foram formadas as sociedades de capitais, nas quais o empreendedor busca através de associações os recursos necessários para o desenvolvimento sustentável do seu negócio.

Segundo Wonnacot e Crusius (2002), as sociedades anônimas ou de capitais remontam muitos séculos e tiveram início na Inglaterra com as concessões de cartas patentes, por disposições 
do Rei, ou do Parlamento. A essas sociedades foram outorgados importantes direitos, entre os quais o monopólio do comércio em certas colônias britânicas, como por exemplo, a East India Company.

Entretanto, Koontz (1971) afirma que muito antes, em 2083 a.C., o Código de Hamurabi já permitia aos babilônios a formação de um tipo de sociedade que conduzia os negócios por muitos anos. Na Roma antiga também existia um tipo de corporação chamada de societae, que era considerada pessoa jurídica e para tal deveria possuir um conselho de administração para poder funcionar.

O atual ambiente competitivo vem exigindo das grandes organizações maior flexibilidade e, principalmente, rapidez nas decisões, sob pena de perderem seus negócios para empresas menores, porém mais ágeis. Para Motta (1994), as empresas transformaram-se em mais complexas e fragmentáveis, tornando o meio empresarial muito dinâmico. Isso exige que as decisões sejam tomadas rapidamente, sob pressão das oportunidades, mas de forma a expor a organização ao mínimo de risco.

Assim, para conduzir a organização em direção ao crescimento, os administradores precisam decidir com rapidez e cautela, superando a concorrência e diminuindo os custos das operações. Esse aumento da eficiência exige que o número de perguntas e respostas - dados e informações - seja cada vez maior para a tomada de decisão.

No caso específico da instituição financeira pesquisada, tais questões têm maior complexidade, pois além de precisar que identifiquem as oportunidades e ameaças do ambiente externo, necessitam acompanhar as mudanças tecnológicas, constituindo uma estrutura interna adequada à realidade, especialmente nos sistemas de gestão e na forma de decidir. Para os bancos, tornou-se fundamental o uso de informações apuradas por sistemas de apoio à decisão - hardwares e softwares - com o objetivo de acelerar todo o processo decisório.

Os bancos são componentes críticos de qualquer economia, pois são provedores de recursos financeiros para os negócios comerciais e industriais, de serviços financeiros para a população e de acesso ao sistema de pagamentos para os agentes. Algumas dessas organizações têm uma missão mais ampla: a de tornar o crédito acessível e de manter a liquidez do mercado (GITMAN, 2002).

A importância dos bancos nas economias dos países é especial pelo fato de que a atividade financeira constitui-se numa indústria universalmente regulamentada e os bancos devem ter autorização dos governos para funcionar. Portanto, é de crucial importância que essas instituições tenham um forte sistema de governança corporativa.

Segundo Marcassa (2004), a governança corporativa no setor bancário brasileiro envolve a maneira pela qual os seus negócios e atividades são dirigidos pelos respectivos conselhos de administração e pelos diretores executivos, à semelhança dos demais setores empresariais, porém com maior rigor, por serem sujeitos às regras determinadas pelo Banco Central do Brasil, que 
influenciam como os bancos devem: determinar seus objetivos; realizar suas atividades diárias; considerar os interesses dos stakeholders; alinhar as atividades corporativas com segurança e observância às leis e regulamentos; e, proteger os interesses dos depositantes.

Os membros do Conselho de administração, além de significar os olhos dos acionistas nos processos de governança, emprestam seus nomes, reputação e prestígio no sentido de tornar confiável a gestão da corporação, garantindo probidade e isenção nas decisões. O conjunto de responsabilidades do conselho de administração envolve questões importantes das corporações, tais como ética, políticas, comunicação com o mercado, responsabilidade social, conflito de interesses, planejamento estratégico, conformação legal e aspectos ambientais, cujas diretrizes quase sempre emanam dos conselhos (MARCASSA, 2004). Um conselho de administração tem importância fundamental no andamento da corporação, na medida em que pode ajudar a manter a corporação fiel aos seus princípios e à observação de conduta pré-determinada, além de contribuir para o desenvolvimento da corporação e da sociedade.

Diante desse contexto, acreditando-se estar determinada a relevância da investigação acadêmica a respeito dos processos decisórios dos Conselhos de Administração dessas corporações, determina-se a formulação da situação-problema desta pesquisa, avaliando os critérios utilizados nas tomadas de decisão, em particular aqueles que podem afetar a estratégia da organização ou que possam comprometer os seus resultados e que, em última instância, conduzem a organização à decadência ou à melhoria contínua de suas práticas de governança, neste caso garantindo a sustentabilidade dos negócios e a segurança na relação com os stakeholders.

Partindo-se da proposta de investigação dos aspectos relacionados à aplicação dos princípios da governança corporativa nas deliberações do Conselho de Administração de um conglomerado bancário brasileiro, esta pesquisa teve como objetivo:

Investigar as deliberações do conselho de administração de um determinado conglomerado bancário brasileiro, buscando avaliar os critérios observados no processo decisório daquele colegiado, verificando se estes estão alinhados com a estratégia definida no modelo de gestão, nas políticas técnicas e nos códigos de melhores práticas de governança corporativa recomendadas pela literatura e pelos órgãos reguladores, e propor um painel de avaliação, considerando-se as boas práticas de governança para esse setor.

Posicionada como uma das principais corporações financeiras do País, a organização eleita para o estudo de caso possui características distintas dos seus principais competidores no sistema bancário brasileiro, não necessariamente nas estratégias de atuação no mercado, mas na composição do seu capital, que acaba orientando a escolha dos membros do seu conselho de administração e, por conseqüência, os integrantes da diretoria executiva. 
Diante de tais particularidades e com o objetivo de tratar e elucidar o problema de pesquisa, atendendo a expectativa do presente estudo, procurou-se direcionar a investigação para responder as seguintes questões:

- As decisões tomadas pelo conselho de administração, no período pesquisado, conduzem a organização a seguir as boas práticas de governança corporativa?

- Os conceitos do BSC contribuíram para apoiar as decisões daquele colegiado?

- Qual é a estrutura conceitual do processo decisório na organização estudada?

- Existe aderência entre as decisões do conselho de administração e os conceitos de sustentabilidade?

No item a seguir, apresenta-se a fundamentação teórica destas questões, com base em uma síntese do rastreamento bibliográfico executado no processo de pesquisa.

\section{Fundamentos teóricos da pesquisa realizada}

Segundo Bornholdt (2005), a governança corporativa vem tomando espaço na literatura e na mídia, especialmente pela atuação de alguns "ativistas" e dirigentes ligados aos fundos de pensão, investidores institucionais e sócios minoritários. Assim, o processo de governança consiste em estudar formas de desenvolver critérios de convivência harmoniosa entre o capital, a gestão e a sociedade na qual a empresa está inserida.

O sentido mais conhecido sobre o conceito de governança corporativa refere-se à relação entre a empresa, os acionistas, os mecanismos e os princípios que governam o processo decisório da gestão, principalmente em relação à proteção dos acionistas. Neste contexto, se destaca o "Relatório Cadbury" de 1992. Nesse documento visualizava-se que os princípios de governança corporativa centravam-se no processo de geração de valor para os acionistas - os shareholders. Porém, mais recentemente, a governança corporativa passou a tratar também das relações com outros grupos que sofrem impacto das decisões, como empregados, fornecedores, clientes e comunidade em geral - os stakeholders (BORNHOLDT, 2005). Essas duas dimensões da governança corporativa - a teoria dos shareholders e a teoria dos stakeholders - foram abordadas neste trabalho.

Carver e Oliver (2002) afirmam que governar e administrar uma empresa são atividades diferentes. Para eles, a governança corporativa deve ser vista como algo externo ao fenômeno da administração e interno ao fenômeno da propriedade. A governança opera num nível que transcende as questões correntes e as tradições específicas da empresa e eleva as pessoas a um nível conceitual superior, onde a responsabilidade pode ser vista com maior clareza. Segundo esses autores, "governar requer - e gera - uma paixão pela liderança, uma liderança não somente sobre os outros como também em nome dos outros". 
Para Steinberg (2003), já existe consenso sobre o fato de que, quanto maior o valor da empresa, mais facilmente se exerce a cidadania e o desenvolvimento dos stakeholders. Para ele, trata-se de um engano imaginar que a prática de boa governança implica somente em acatar regulamentos.

Andrade e Rossetti (2004) entendem governança corporativa como sendo um constructo, isto é, uma categoria que somente pode ser compreendida a partir do estudo de um conjunto de conceitos composto por variáveis de diversos campos do conhecimento, tais como economia, finanças, contabilidade, teoria organizacional, direito, sociologia, ética, comunicação e teoria da informação.

Pelo exposto, pode-se depreender que o tema governança corporativa ainda é extremamente complexo e de natureza multidisciplinar. Diante dessa multiplicidade de variáveis, optou-se por selecionar as teorias correntes que poderiam auxiliar a compreensão do fenômeno estudado neste trabalho.

A Teoria da Agência tem como precursores dois estudiosos, Berle e Means, que realizaram uma extensa pesquisa nos anos 30 em inúmeras empresas norte-americanas e constataram que as organizações típicas do Século XIX eram dirigidas pelos seus proprietários ou seus prepostos e, em essência, sua dimensão estava limitada ao patrimônio pessoal dos indivíduos no controle.

$\mathrm{Na}$ análise da separação entre propriedade e controle, os autores historiam que as corporações evoluíram para estruturas organizacionais mais complexas, em função de um novo sistema fabril, que teve como efeito:

- um número crescente de trabalhadores sob o comando de um coordenador; e,

- uma nova forma organizacional, de caráter quase público cuja propriedade é pulverizada entre diversos acionistas, detentores de pequenas quantidades de títulos - as ações.

Uma outra vertente apresentada por SCHERER (2003), de caráter crítico, cuida do processo social que determina a alocação dos recursos e dos investimentos. Trata-se do exercício do poder no interior da empresa que transborda, em suas conseqüências, para toda a sociedade, e esse poder se traduz na forma, no objetivo, no prazo do investimento e na forma de repartição dos dividendos como parcela dos lucros que serão distribuídos aos investidores e acionistas.

Rodrigues e Mendes (2004) abordam o assunto sob o mesmo enfoque econômico, ao afirmarem que existe certa dualidade de conceitos, e definem as práticas da governança societária e da governança corporativa, a primeira como base estrutural da segunda. Para esses autores, a governança societária se fundamenta no estabelecimento dos vínculos necessários entre os donos de capital, acionistas ou cotistas, no sentido de definir a estrutura e a organização da empresa, onde investir os recursos, de modo a gerar resultados, apresentando crescimento e valorização dos capitais aplicados. 
Segundo o Relatório Cadbury (1992) in Rodrigues (2003), a governança corporativa é o sistema através do qual as companhias são dirigidas e controladas; porém um conceito mais abrangente foi cunhado pela Organização para Cooperação e Desenvolvimento Econômico (2005):

Governança corporativa compreende a estrutura de relacionamentos e correspondentes responsabilidades entre um grupo central formado pelos acionistas, membros do conselho de administração, e gestores designados para melhor promover o desempenho competitivo necessário para atingir os objetivos principais da corporação.

Para Rechtman et al (2004), a definição da CVM é relevante na medida em que demonstra uma preocupação com o desenvolvimento do mercado de capitais, porém, mesmo que uma corporação observe os códigos de governança corporativa, se não apresentar bons resultados, os investidores tenderão a preteri-la nas suas escolhas de portfolio. Esta observação é típica de um processo de transição de modelos de avaliação de investimentos, indicando que hoje o principal objetivo do investidor é auferir rentabilidade sobre cada empreendimento, e que uma minoria deles estaria disposta a pagar um prêmio pelas ações de empresas apenas em função de estarem adotando boas práticas de governança corporativa.

O modelo anglo-saxão se caracteriza pela pulverização e a separação da propriedade e da gestão. Trata-se de um modelo fortemente orientado para o mercado e também por ele monitorado, existindo outros mecanismos externos de orientação, como por exemplo, a estrutura regulatória de proteção aos acionistas. O modelo fundamenta-se no Direito e um importante instrumento regulatório é a lei Sarbanes Oxley nos Estados Unidos da América e o City Code na Grã Bretanha.

O modelo alemão tem como característica a origem do capital acionário que vem das instituições bancárias. Os exigíveis de longo prazo são uma alternativa de alavancagem de negócios mais praticada que a emissão ações para subscrição pública. Isto quer dizer que o modelo de governança é predominantemente bank oriented.

O modelo japonês possui alguma semelhança com o modelo de governança corporativa praticado na Alemanha, e sua maior semelhança está na importância dos bancos na estrutura de capital, no monitoramento e no controle das corporações; com a prática do consenso no processo de gestão; e com a consideração de múltiplos interesses. Um aspecto a ser considerado está na função do conselho de administração, que se limita a observar e aconselhar as grandes decisões, acompanhando os resultados corporativos, buscando não intervir.

O modelo latino-europeu é constituído pela França, Itália, Espanha e Portugal. Tem como diferença relevante o fato de que a propriedade mantém-se concentrada, geralmente na forma de controle por consórcios de acionistas, detentores de blocos de ações. Essa característica se reflete na sobreposição entre a propriedade e gestão, pois a concentração acionária é importante fator de definição da composição e funcionamento dos conselhos de administração. De acordo com Andrade 
e Rossetti (2004), esse modelo não estimula o desenvolvimento do mercado de capitais, alijando os pequenos investidores.

Para esses autores, o modelo latino-americano tem como características importantes fatores relacionados com o setor público e o setor privado. O desenvolvimento da economia foi promovido pelo Estado, por meio da criação de um grande número de empresas estatais, muitas delas privatizadas nas duas últimas duas décadas. Uma outra característica está no elevado grau de concentração patrimonial e, mesmo nas maiores sociedades de capital aberto, o controle se encontra nas mãos de grupos familiares. Ainda, verifica-se o papel que os grupos financeiro-industriais desempenham no desenvolvimento privado. Há um controle comum na operação dos negócios, desenvolvendo um portfolio de negócios não necessariamente relacionados. Os resultados dos negócios mais lucrativos sevem de "carro-chefe" para financiar novos empreendimentos carentes de capital. Um relevante fator verificado nesse modelo é a sua falta de transparência das operações internas, sendo vista como o obstáculo ao acesso a alternativas de investimentos de mais baixo custo.

Entre os compromissos de longo alcance das corporações, Andrade e Rossetti (2004) destacam dois, referentes a questões sociais e ambientais; 1. atenção para os efeitos globais dos negócios e do crescimento exponencial de suas escalas e não apenas para os impactos pontuais nos locais onde eles se realizam; e 2. visão transgeracional, com ampla extensão do horizonte estratégico, conciliando a produção para a satisfação dos mercados atuais com os direitos das futuras gerações às provisões necessárias a padrões de vida melhores que os atualmente vigentes.

Utilizou-se a visão desses autores para tratar deste tópico, dada sua pertinência com os conceitos da sustentabilidade aplicáveis em ambiente corporativo. A seguir são abordados conceitos sobre Balanced Scorecard, considerando-se que a análise do assunto interliga-se ao tema principal a governança corporativa - e contribui para o entendimento do trabalho como um todo.

\subsection{O Balanced Scorecard}

De acordo com Olve et al (2001), em seu conceito original, o Balanced Scorecard (BSC) servia para a empresa ser considerada a partir de quatro perspectivas vitais: financeira; processos internos; clientes; e, aprendizagem e crescimento. Propunha-se criar uma espécie de painel de controle operacional de curto prazo vinculado à visão de longo prazo e à estratégia do negócio. Em outras palavras, a organização passava a controlar e monitorar as operações do dia-a-dia, considerando que elas afetam o desenvolvimento futuro.

O conceito do BSC baseia-se sobre três dimensões: ontem, hoje, amanhã. OLVE et al (2001, p. 6) acrescentam que: “O que fazemos de hoje para amanhã talvez não tenha nenhum impacto 
financeiro que possa ser notado até depois de amanhã’. Isto significa que o foco da empresa foi ampliado, tornando-se relevante observar as proporções-chave não financeiras, pois são estas que podem afetar a sustentabilidade do negócio. O BSC consiste em uma metodologia para o gerenciamento dos negócios, que acrescentava outras dimensões além do tradicional quadro de indicadores de desempenho financeiro utilizados tradicionalmente, introduzindo como novidade à possibilidade de ligação do desempenho dos processos à estratégia empresarial. O modelo desenvolvido se traduz pela transmissão da estratégia em todos os níveis da organização, estabelecendo-se um conjunto de indicadores financeiros e não-financeiros. Esse conjunto constitui uma espécie de painel de controle, com o objetivo de auxiliar o gestor na "pilotagem" da empresa.

Os precursores do BSC, Kaplan e Norton (1997), apesar de dividirem o acompanhamento e a avaliação da gestão empresarial nas quatro citadas perspectivas (financeira; clientes; processos; e, aprendizado e crescimento), alertam que essa divisão constitui um modelo genérico, não impedindo que se faça um redimensionamento, acrescentando-se ou redistribuindo-se novos elementos.

A Figura 1 ilustra o modelo genérico, suas perspectivas e as definições das relações de causa e efeito.

Figura 1 - As quatro perspectivas do $B S C$.

SISTEMA BALANCEADO DE MÉTRICAS

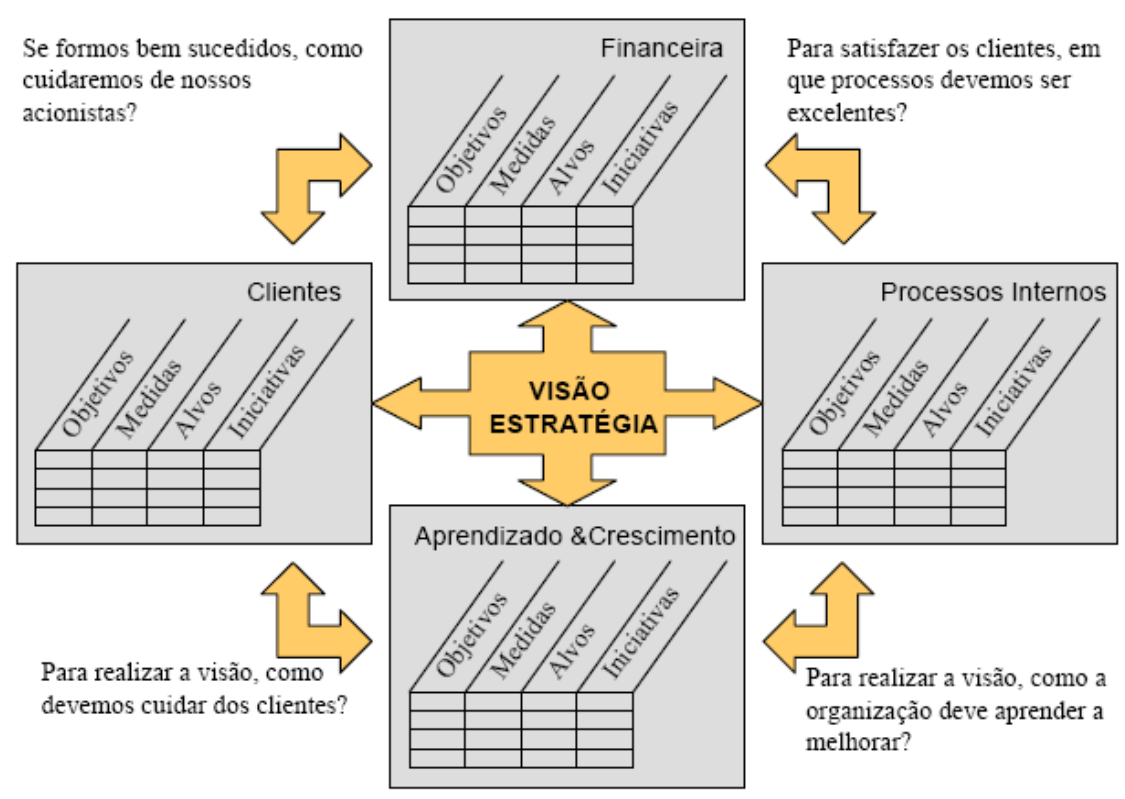

Fonte: Kaplan e Norton (1997).

As quatro perspectivas definidas pelo $B S C$ podem ser construídas em cada organização a partir de respostas que venham a ser dadas a quatro perguntas fundamentais, associadas a cada uma das referidas dimensões, a saber: 
- Perspectiva Financeira: se formos bem sucedidos como cuidaremos de nossos acionistas?

- Perspectiva Clientes: para realizar a visão, como devemos cuidar dos clientes?

- Perspectiva Processos Internos: para satisfazer nossos clientes (e acionistas) em quais processos de negócios devemos ser excelentes?

- Perspectiva Aprendizado e Crescimento: para realizar a visão como a organização deve aprender a melhorar? E, Como sustentar a capacidade de mudar e melhorar?

As respostas a cada uma das perguntas formuladas devem vir acompanhadas dos respectivos propósitos, indicadores, metas e iniciativas, devidamente integradas à estratégia formulada pela organização. Os indicadores financeiros de desempenho buscam medir se a estratégia de uma empresa e sua execução, contribuem para a melhoria dos resultados financeiros e devem sintetizar as conseqüências imediatas das ações executadas.

Na perspectiva Clientes, o BSC permite identificar os segmentos de clientes e mercados onde a organização pretende competir e indica as medidas de desempenho a eles associados. Além de medidas essenciais de resultados, devem-se incluir também medidas de propostas de valor que serão oferecidas aos segmentos-alvo de clientes e/ou mercado-alvo.

Na perspectiva Processos Internos deve-se possibilitar a identificação dos processos internos críticos onde a organização pode alcançar a excelência, oferecendo propostas de valor capazes de atrair e reter clientes em segmentos-alvo do mercado e satisfazer as expectativas dos acionistas quanto ao retorno financeiro. Nesta perspectiva ficam evidenciadas duas diferenças básicas entre a abordagem tradicional e a abordagem do $B S C$ :

- Na abordagem tradicional, o foco se mantém na melhoria dos processos existentes; e,

- Na abordagem através do BSC, processos inteiramente novos e inovadores costumam ser identificados onde a organização pode atingir a excelência para atender aos objetivos propostos.

A quarta perspectiva - Aprendizado e Crescimento - parte da suposição de que as organizações não são capazes de atingir suas metas de longo prazo para clientes e processos internos utilizando as tecnologias e capacidades atuais. Assim, a organização deve investir no aprimoramento dos colaboradores, no aperfeiçoamento da tecnologia de informação (TI) utilizada e no alinhamento dos procedimentos e rotinas organizacionais.

Kaplan e Norton (1997) afirmam que as quatro perspectivas propostas devem funcionar como um modelo e não como uma proposta "fechada", não existindo qualquer equação matemática garantindo que as quatro perspectivas são necessárias ou suficientes. Dependendo das circunstâncias e da estratégia é possível identificar a necessidade de se agregar outras perspectivas. Sobre a adição de novas dimensões ao BSC, Olve et al (2001) mencionam os exemplos de empresas 
como a SKANDIA e a ABB que decidiram introduzir uma quinta perspectiva, focalizada nos recursos humanos. Entretanto, os autores concluíram que o modelo de Kaplan e Norton (1997) é mais vantajoso, pois as suas quatro perspectivas são abrangentes e, qualquer outra que se queira acrescentar, pode ser contemplada dentro daquelas.

\section{Procedimentos metodológicos da pesquisa}

Este estudo classifica-se quanto à sua natureza como pesquisa aplicada, pois teve o objetivo de solucionar um problema prático no campo da governança corporativa em um conglomerado financeiro composto por diversas atividades, que abrange participações em inúmeras empresas coligadas e controladas, em diversos ramos, tais como seguros, previdência, capitalização, administração de recursos de terceiros, serviços de tecnologia, cartões de crédito, dentre outros.

Quanto à forma de abordagem do problema, classifica-se como uma pesquisa qualitativa. Porém, em algumas etapas do estudo quantifica os resultados, produzindo indicadores verificáveis matematicamente e, em outras etapas, torna-se predominantemente qualitativa, ou seja, caracterizase, segundo Deslandes (2000), por responder a questões particulares onde o nível de realidade não pode ser totalmente quantificado, trabalhando com: motivos, crenças, valores, comportamentos e percepções individuais. Procura, pois, estabelecer relações entre os fenômenos observados comparando-os com outros fatos já pesquisados e, especialmente, com a literatura consagrada.

Quanto aos objetivos, classifica-se em exploratória e descritiva. A pesquisa é exploratória porque busca relatar com precisão a situação e procura descobrir relações existentes entre os elementos que a compõem. Também é descritiva porque relata observações, registros e análises, correlacionando fatos e variáveis, buscando descobrir, com a precisão possível, a freqüência com que os fenômenos ocorrem, sua relação e conexão com outros fenômenos, bem como sua natureza e características.

Quanto aos procedimentos, trata-se de um estudo de caso referenciado por pesquisa bibliográfica. A Figura 2 apresenta o modelo esquemático desenvolvido para a presente pesquisa. 
Figura 2 - Modelo esquemático da pesquisa, quanto à sua metodologia.

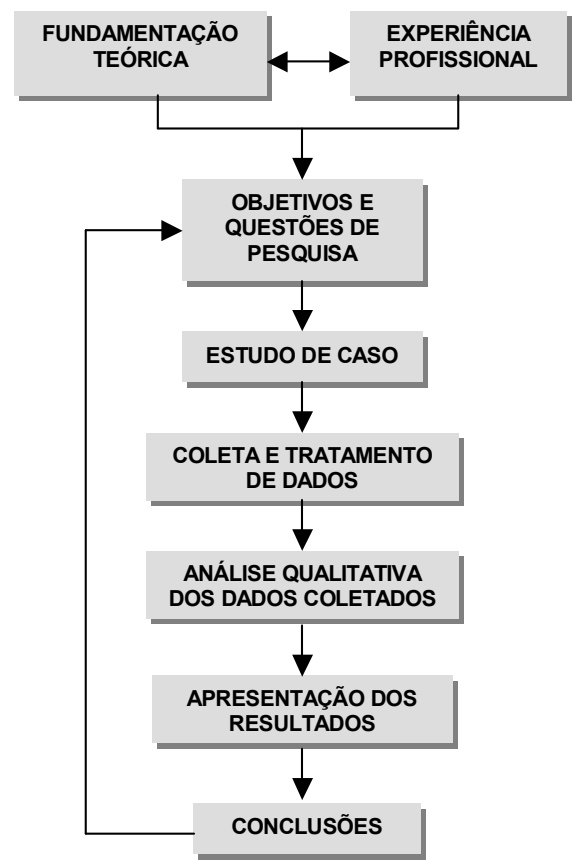

Fonte: o autor.

\section{O estudo de caso}

Neste item, com base na metodologia definida, é desenvolvido o estudo de caso da entidade financeira escolhida pelo pesquisador, oferecendo o detalhamento dos dados coletados através da tabulação, interpretação e análise dos resultados obtidos.

Os dados gerais da organização, principais aspectos de sua estrutura e funcionamento, foram obtidos por meio de pesquisa em documentos disponíveis na sede da organização, compreendendo as atas de registro das reuniões do conselho de administração, estatuto social, estratégia corporativa, discurso institucional, referenciais de gestão, política geral de negócios, plano diretor. Também foram realizadas consultas ao site da organização, onde foram analisados os relatórios anuais e de responsabilidade sócio-ambiental, publicações internas (revistas, encartes, folhetaria etc), além de outros veículos de acesso público.

Considerando a natureza estratégica de alguns importantes documentos a que o pesquisador teve acesso, utilizados somente por integrantes de altos escalões decisórios da instituição, foi assumido compromisso de não ser divulgada a razão social da entidade bancária. Independentemente desta limitação, acredita-se que os objetivos do estudo não foram prejudicados, pois os documentos analisados permitem identificá-los com o problema e com as questões de pesquisa formuladas, conferindo o desejado rigor científico que se exige para trabalhos desta natureza. A organização, pelo que se conseguiu avaliar através dos documentos que foram 
consultados na pesquisa, vem procurando adotar gradativamente padrões de governança que sejam referenciais para o mercado. Por exemplo, recentes reformas no seu estatuto social contemplaram regras que garantem o equilíbrio de direitos entre os acionistas, inclusive minoritários, a transparência e a prestação de contas do negócio, que balizam as ações de todos os níveis decisórios, unidades e comitês. O Conselho de Administração (CA) é composto por sete membros, com mandato unificado de um ano, sendo permitida a reeleição, o que atende, acredita-se, às recomendações previstas no Código de Melhores Práticas de Governança Corporativa (IBGC, 2004). Dos sete membros, dois são indicados pelos acionistas minoritários, um por representante de clubes de investimentos, e os demais pelo majoritário. O conselho fiscal é composto por cinco membros, dentre os quais dois são indicados por acionistas minoritários e os demais pelo controlador. Além do conselho fiscal, o sistema de fiscalização e auditoria do conglomerado é composto pela auditoria independente e pela auditoria interna, e o comitê de auditoria. A organização, por integrar a indústria financeira, está sujeita ainda à regulação e fiscalização do Banco Central do Brasil.

O comitê de auditoria, órgão estatutário constituído em conformidade com regulamentação do Conselho Monetário Nacional (CMN) possui atribuições de fiscalização e controle, assessorando o conselho de administração (CA) no exercício de suas funções. É composto por três membros efetivos e um suplente, não pertencentes ao quadro da organização, com mandatos de três anos alternados e eleitos pelo CA, sendo que pelo menos um dos titulares é escolhido pelos conselheiros eleitos pelos acionistas minoritários. Esse comitê possui as seguintes atribuições:

- assessorar o CA no que concerne ao exercício de suas funções de auditoria interna e fiscalização;

- supervisionar as atividades e avaliar os trabalhos de auditoria independente;

- supervisionar as atividades do auditor geral e avaliar os trabalhos de auditoria interna; e,

- exercer suas atribuições junto às empresas controladas pelo banco.

Recentemente a organização aprimorou a sistemática de verificação de conformidade dos processos das unidades táticas e operacionais do Brasil. Passou a estabelecer políticas de conformidade e controles internos, além de monitorar permanentemente sua observância. As unidades no exterior foram contempladas também recentemente com um programa de compliance, visando uniformizar a abordagem às normas e otimizar o nível de aderência à regulamentação local. O conglomerado realiza a gestão de riscos de mercado, liquidez, crédito e operacional de maneira consolidada e alinhada às melhores práticas adotadas no mercado financeiro internacional, procurando assegurar a adequada segregação de funções e eficiência à gestão dos riscos. $\mathrm{O}$ gerenciamento de riscos é feito fora das unidades de negócios, cabendo ao Comitê de Risco Global 
- fórum composto pelos membros do conselho diretor, diretores e executivos de diversas áreas - a definição das estratégias de gestão, inclusive nas subsidiárias integrais.

Como é possível depreender dessa abordagem, existem dois importantes comitês que compõem a estrutura de todos os processos decisórios da empresa: o de Risco Global e o de Auditoria. Enquanto o comitê de auditoria é um órgão de assessoramento ao conselho de administração, o de Risco Global tem caráter executivo e é constituído por um conjunto de subcomitês e comissões, operacionalizado por meio de um modelo integrado que supera as exigências dos dispositivos legais estabelecidos pelas entidades regulamentares. Com a integração da estrutura de gestão de riscos de mercado, liquidez, operacional e de crédito do conglomerado, o comitê tornou-se responsável pelo gerenciamento global dos riscos, gerando um aumento de sinergia de processos e de grau de especialização, proporcionando, entre outros aspectos, maior precisão na mensuração dos riscos e, por conseguinte, melhor alocação de capital. Cada um dos riscos geridos apresenta ênfase de gestão complementar às demais categorias, permitindo realizar a gestão global dos riscos aos quais a organização está sujeita.

O gerenciamento dos riscos de gestão de ativo e passivo (ou liquidez e mercado), de crédito e operacional, são segregados das unidades de negócios. Assim, a instituição adota uma visão consolidada dessas categorias e, em seu gerenciamento, considera a interdependência entre elas de forma integrada. Essas três categorias estão subdivididas em duas comissões e um sub-comitê:, a comissão de Ativos e Passivos; a Comissão de Risco de Crédito e o sub-comitê de Risco Operacional. Essa modelagem permite identificar na estrutura de decisão de riscos o principal instrumento de apoio às decisões nos níveis gerenciais (tático) e no nível estratégico (conselho de administração). Os riscos de liquidez e mercado são analisados pela comissão de Gestão de Ativos e Passivos, visando minimizar os riscos relativos à volatilidade das taxas de juros e câmbio, de variações significativas no preço dos ativos e de oscilações no mercado de ações e de commodities. Para o gerenciamento do risco de mercado as operações comerciais e de tesouraria são segregadas das operações de trading, ambas com limites e estratégias próprias. Quanto ao risco de liquidez especificamente, a corporação mantém reservas formadas por títulos públicos federais de fácil conversão em moeda. Essas reservas são consideradas na elaboração do processo orçamentário de modo a atender às necessidades de seu fluxo de caixa. Afora isso, mantém um plano de contingência elaborado pela referida comissão para fazer frente a eventuais crises nos mercados financeiro nacional ou internacional.

Cabe observar que na gestão de riscos de mercado e liquidez, a entidade utiliza metodologias estatísticas como o Valor em Risco (V@R) e de simulação, análise de estresse e sensibilidade. A gestão da liquidez é realizada, principalmente, pelo monitoramento do fluxo de caixa em função de um limite mínimo compatível com o grau de exposição ao risco decorrente da 
estrutura patrimonial da instituição e da análise das condições de mercado. Esse comitê, em novembro de 2003, estabeleceu um indicador estratégico chamado de Disponibilidade de Recursos Livres - DRL - que associa a geração e o uso de recursos livres. Em 2004 foi estabelecido o nível mínimo de $25 \%$ para esse indicador. Tal patamar de liquidez estrutural é considerado suficiente para a realização das operações comerciais, sem exigir da tesouraria captações adicionais. O plano de contingência de liquidez é outro instrumento idealizado pelo comitê, onde estão explicitadas as ações e medidas a serem adotadas no caso da projeção do fluxo de caixa indicar níveis de liquidez inferiores ao limite mínimo definido.

Quanto aos riscos de crédito, todas as decisões a isto relacionadas são tomadas de forma colegiada e de acordo com as diretrizes e as normas organizacionais instituídas, que visam assegurar a assunção de riscos em níveis adequados. Para a identificação dos riscos associados à carteira de crédito são adotados modelos tais como análise de portfolio de diversas visões, acompanhamento da evolução qualitativa e quantitativa da carteira e níveis de concentração, entre outros.

Para a gestão do risco operacional, a organização pesquisada tem um modelo próprio que objetiva identificar as situações de exposição aos riscos, classificar e mensurar perdas operacionais, mitigar riscos e incentivar a discussão acerca do risco operacional em todo o conglomerado. $\mathrm{O}$ estágio do processo, em 2004, permitia comparar os efeitos sobre a alocação de capital com a abordagem básica para risco operacional. O modelo de gerenciamento do risco operacional adotado identifica e avalia os riscos, suas conseqüências financeiras e causas, sob quatro fatores: processos, pessoas, sistemas e eventos externos.

Ao adotar os referidos modelos internos de avaliação de riscos para alocação de seus capitais, a corporação está adaptando suas estruturas patrimoniais ao cumprimento da regulação do Banco Central do Brasil com base nas exigências do chamado "Novo Acordo da Basiléia" (ou “Basiléia II"). Esse marco prudencial representa uma evolução do "Basiléia I", acordo firmado em 1988 pelo Comitê da Basiléia (subordinado ao BIS - Bank of International Settlements), que serviu para introduzir um padrão uniforme para cálculo do capital regulatório mínimo requerido para os bancos internacionalmente ativos, sendo que mais de 100 países adotaram este padrão, entre eles o Brasil. O "Basiléia II", finalizado em 2004, objetiva prover uma abordagem de gerenciamento de riscos mais completa e sofisticada, estando fundamentado em três pilares para assegurar a segurança e confiabilidade do sistema financeiro internacional: abordagens múltiplas para a o cálculo do capital mínimo; melhoria do exame do órgão supervisor; e, maior transparência para o mercado.

Ao comparar-se o modelo de gestão de riscos da organização pesquisada com os dispositivos legais e regulamentares requeridos pelas entidades reguladoras do mercado, depreendese que seu modelo vai além do cumprimento das normas, pois sua matriz de riscos inclui categorias 
não ainda exigidas e implementa níveis de segregação superiores aos recomendados pelos normativos vigentes. Em seu posicionamento estratégico, a organização objeto do presente estudo formalmente declara em seus documentos oficiais os vetores da sustentabilidade - econômico, social e ambiental - de forma a buscar garantir a criação de valor no longo prazo.

Segundo práticas empresariais tradicionais, implementa modelos de gestão como: planejamento estratégico, governança corporativa, gestão de riscos, responsabilidade socioambiental e indicadores de fatores críticos de sustentabilidade, com política consolidada de relacionamento com partes interessadas, cujos destaques são a Carta de Princípios de Responsabilidade Sócio-ambiental e o Painel de Ações Sociais. Uma melhor avaliação desse assunto pode ser obtida através da análise da decomposição das decisões do conselho de administração da organização e do Painel de Avaliação das Práticas de Governança Corporativa.

\section{Considerações finais}

A experiência de realização deste estudo permite a construção de algumas conclusões, tanto no nível da pesquisa empírica, como em relação à investigação teórica nele contida. Estas conclusões, aqui apresentadas na forma de inferências sobre o estudo realizado, não caracterizam, no entanto, considerações que sejam passíveis de generalizações, uma vez que a pesquisa empírica limitou-se à execução de um estudo de caso.

A primeira questão de pesquisa levantada diz respeito às decisões tomadas pelo conselho de administração da organização investigada e sua articulação no sentido de conduzi-la à observância das boas práticas de governança corporativa. É imperativo registrar que a pesquisa realizada constatou a existência de uma estrutura formal e bem definida de governança corporativa instalada na organização, com uma clara orientação de aderência ao Código Brasileiro das Melhores Práticas de Governança Corporativa, proposto pelo IBGC (2004).

A pesquisa realizada constatou que o conglomerado estudado possui uma estrutura legal de governança corporativa, em perfeita consonância com o que recomendam as abordagens de CARVER e OLIVER (2002), SILVEIRA (2002), STEINBERG (2003), VENTURA (2003), SCHERER (2003), FONTES FILHO (2005). Esta estrutura, conforme já mencionado, é composta por um conselho de administração (CA), um conselho fiscal, um comitê de auditoria, um auditoria independente, uma auditoria interna e um comitê de risco global.

É importante ressaltar que a governança corporativa objeto deste estudo realiza ainda as atividades de gerenciamento de riscos, de forma consolidada e alinhada às melhores práticas adotadas no mercado financeiro internacional, alcançando sete categorias de riscos: de conjuntura, 
de crédito, de mercado, de liquidez, operacional, legal e de imagem, conferindo à sua estrutura dimensões semelhantes às estudadas por RECHTMAN et al (2004).

Examinando-se as decisões tomadas pelo conselho de administração da organização estudada, conclui-se que estas se alinham perfeitamente ao concurso necessário às boas práticas de governança corporativa, tanto no nível das abordagens teóricas analisadas, quanto no plano do cotidiano empírico de suas principais concorrentes.

Conclui-se ainda, acerca desta questão, que a investigação a respeito da observância das boas práticas de governança corporativa no processo decisório de um determinado conglomerado financeiro, utilizando a metodologia do estudo de caso, ou mesmo a dos casos múltiplos, deve levar em consideração as especificidades da indústria bancária, as quais ampliam as obrigações dos dirigentes e conselheiros dessas entidades quando comparadas com as de outras companhias. Conforme evidenciado nesta pesquisa, isto acontece porque as instituições financeiras possuem quase sempre menor estrutura de capitais próprios em relação aos capitais alheios e, também, pelo fato de oferecerem riscos adicionais aos investidores na razão direta da forma como são administrados os recursos captados.

A segunda questão de pesquisa construída nesta dissertação diz respeito ao suporte da metodologia $B S C$ no processo de tomada de decisões da organização investigada. Neste aspecto, constatou-se que a organização utiliza a ferramenta $B S C$ desde 2001 e que esta tem se demonstrado um mecanismo sinergístico de articulação entre suas estratégicas de longo prazo e suas ações de curto prazo. Na organização estudada, o BSC é utilizado na formulação de cinco faixas de estratégias organizacionais (Financeira, Sociedade, Clientes, Processos Internos e Comportamento Organizacional), tal como prescrevem as abordagens de KAPLAN e NORTON (1997), KAPLAN e NORTON (2000), OLVE et al (2001) e KAPLAN e NORTON (2004).

Em consonância com estas abordagens, constatou-se que a ferramenta $B S C$ tem permitido à organização a categorização e suporte das decisões tomadas pelo conselho de administração, tanto no plano das perspectivas por ela abordada, como no esboço das boas práticas de governança corporativa.

Dentre os aspectos que realçam a importância do $B S C$, é importante reconhecer, a título de conclusão, que pelo menos três deles emprestam imenso significado às operações da organização estudada, quais sejam: (a) o resumo em um relatório de gestão dos elementos aparentemente discrepantes do programa de competitividade da empresa; (b) a utilização de diferentes dimensões de desempenho, vinculadas através de relações de causa e efeito; e (c) a disponibilização de informações que possibilitam os tomadores de decisão realizar uma avaliação sucinta do desempenho global da organização. 
Conclui-se, portanto, com relação a esta questão, que o uso do $B S C$ como ferramenta de suporte à tomada de decisão caracteriza um esforço da entidade em ampliar o escopo de sua estrutura de governança corporativa, modelo este que pode (em função das várias vantagens já examinadas) ser estendido a outras organizações congêneres e mesmo a entidades de outra natureza.

As conclusões relativas à terceira questão de pesquisa elaborada nesta dissertação, questionando-se sobre a estrutura conceitual do processo decisório operado pela organização investigada, possuem lastro conceitual nas abordagens apresentadas por SIMON (1965), DAVIS e OLSON (1987), BETLHEM (1987), ANSOFF (1990), McGee e PRUSAK (1994), PEREIRA e FONSECA (1997).

Desse modo, conclui-se que a organização opera duas tipologias de estrutura (a organizacional e a funcional), modelando decisões colegiadas e por consenso, todas elas vinculadas ao conceito de governança corporativa. Constata-se que esse instituto tem, visivelmente, a finalidade de proteger a organização de eventuais conseqüências quanto a alguma tomada de decisão sem o rigor técnico necessário. Em termos de modelagem conceitual, essa arquitetura de decisão se inspira fortemente no modelo de Simon (1965), o qual prevê quatro etapas para o processo decisório: inteligência, concepção, escolha e "feed back".

Ainda em termos de conclusões acerca desta questão, é importante reconhecer que, na organização estudada, as decisões e os processos decisórios envolvem quase sempre um grande número de pessoas, um conjunto complexo de antecedentes, bem como uma análise mais complexa em termos de preferências e oportunidades.

Na seqüência, a quarta e última questão de pesquisa constante desta investigação, refere-se aos aspectos de aderência entre as decisões do conselho de administração e os conceitos de sustentabilidade. Os marcos conclusivos desta questão foram fundamentados em CMMAD (1991), BRÜSEKE (1995), FURTADO (1996), entre outros.

Com base nas constatações da pesquisa, conclui-se que existe um forte grau de aderência e/ou sustentabilidade, comprovado através de Carta de Princípios de Responsabilidade Socioambiental, que institui termo de compromisso com seus funcionários, colaboradores, fornecedores, parceiros, credores, sócios, acionistas, concorrentes, comunidade e governo.

\footnotetext{
Abstract

About the main concepts regarding corporate governance, using BSC - Balanced Scorecard as a decision process analysis tool, evaluating the decisions of a Brazilian financial holding's administration board. The objective is to investigate that board's decisions, evaluating the criteria used in the decision process and their adherence to the management model, policies and best practices in corporate governance. Based on ordinary and extraordinary reports of assemblies held between 2003 and 2004, the research analyzes the decisions taken by the board of directors, according to the corporate governance best practices and the management model adopted - the
} 
Balanced Scorecard. Results offer conclusive remarks about the company, indicating: (a) the existence of a clear, formal and well defined structure of corporate government; (b) a relevant contribution of BSC's concepts, supporting the decisions taken by the board; (c) the characterization of conceptual structure of the decision process operated by the company; and (d) the strong adherence between the company board's decisions and the modern concepts of sustainability.

Keywords: corporate governance; sustainable development; balanced scorecard.

\section{Referências}

ANDRADE, A; ROSSETTI, J.P.; Governança corporativa: fundamentos, desenvolvimento e tendências. São Paulo: Atlas, 2004.

ANSOFF, H.I. A nova estratégia empresarial. São Paulo: Atlas, 1990.

BERLE JR., ADOLF A. \& MEANS, GARDINER C. A propriedade privada na economia moderna. Rio de Janeiro: Ipanema, 1957.

BORNHOLDT, W. Governança na empresa familiar. Porto Alegre: Bookman, 2005.

BRÜSEKE, J.F. O problema do desenvolvimento sustentável, in Desenvolvimento e natureza: estudos para uma sociedade sustentável. Recife: Córtez, 1995.

CANTIDIANO, L.L; CORREA, R.(Organizadores). Governança corporativa: empresas transparentes na sociedade de capitais. São Paulo: Lazuli, 2004.

CARVER, J.; OLIVER, C. Conselhos de administração que geram valor. São Paulo: Pensamento-Cultrix, 2002.

COMISSÃO MUNDIAL SOBRE MEIO AMBIENTE E DESENVOLVIMENTO (CMMAD). Nosso futuro comum. Rio de Janeiro: FGV, 1991.

DAVIS, G. B.; OLSON, M. Sistemas de información gerencial. Bogotá: Mc Graw Hill, 1987.

DESLANDES, S. F. Pesquisa social: teoria, métodos e criatividade. Petrópolis: Vozes, 2000.

FERREIRA, M.C. Serviço de atendimento ao cliente: o que é ? Como avaliá-lo ? Esboço de uma abordagem metodológica em ergometria. Revista multitemas, UNB, Brasília, nº16, p.122/144, maio 2002.

FONTES FILHO, J. R. Estudo de validade de generalizações práticas de governança corporativa ao ambiente de fundos de pensão: uma análise segundo as teorias da agência e institucional. Tese de doutorado da Escola Brasileira de Administração Pública e de Empresas da Fundação Getúlio Vargas - FGV, 2005.

FURTADO, C. O mito do desenvolvimento econômico. São Paulo: Paz e Terra, 1996.

GITMAN, L.J. Princípios de administração financeira. São Paulo: Harbra, 2002.

INSTITUTO BRASILEIRO DE GOVERNANÇA CORPORATIVA (IBGC). Código das melhores práticas de governança corporativa. Novembro de 2004. Disponível em: <www.ibgc.org.br >. Acesso em março de 2004.

KAPLAN, R. S.; NORTON, D. P; A estratégia em ação: Balanced Scorecard. Rio de Janeiro, Campus, 1997. .Organização orientada para a estratégia. Rio de Janeiro, Campus, 2000.

Mapas estratégicos: convertendo ativos intangíveis em resultados tangíveis. Rio de Janeiro: Elsevier, 2004.

MARCASSA, A.C. Mecanismos de governança corporativa em bancos. Revista de Administração de Empresas. São Paulo, Disponível em: <www.rae.br>. Acesso em: março de 2004. 
McGEE, J.; PRUSAK, L. Gerenciamento estratégico da informação: aumente a competitividade e a eficiência de sua empresa utilizando a informação como uma ferramenta estratégica. Rio de Janeiro: Campus, 1994.

MOTTA, P R.; Reengenharia: utilidades e futilidades da nova onda administrativa. Porto Alegre: Age, 1994.

OLVE, N.; ROY, J.; WETTER, M. Condutores da performance: um guia prático do uso do Balanced Scorecard. Rio de Janeiro: Qualitymark, 2001.

ORGANIZAÇÃO PARA COOPERAÇÃO E DESENVOLVIMENTO ECONÔMICO - OCDE. The OECD Principles of Corporate Governance. Disponível em: <www.oecd.organização/daf/governance/principles.htm>. Acesso em 8 nov 2005.

PEREIRA, M.J.L.B.; FONSECA, J.G.M. Faces da decisão: as mudanças de paradigmas e o poder de decisão. São Paulo: Makron Books, 1997.

RECHTMAN, M.; FONTES FILHO, J.R.; GAMMINO, F. Governança corporativa aplicada ao contexto empresarial brasileiro. Rio de Janeiro: Papel Virtual, 2004.

RODRIGUES, A.T. Governança corporativa: quando a transparência passa a ser uma exigência global. In: IX Convenção de Contabilidade do Rio Grande do Sul. Gramado, 13-15 agosto 2003.

RODRIGUES, J.A.; MENDES, G.M. Governança corporativa: estratégia para geração de valor. Rio de Janeiro: Qualitymark, 2004.

SCHERER, A.L.F. O modelo norte-americano de governança corporativa: gênese, instrumentos e conseqüências. Porto Alegre: Ensaios FEE Fundação de Economia e Estatística Siegfried Emanuel Heuser, p.295-572, 2003.

SILVEIRA, A.M. Governança corporativa, desempenho e valor da empresa no Brasil. São Paulo: dissertação de mestrado da Faculdade de Economia Administração e Contabilidade da Universidade de São Paulo - USP, 2002.

SIMON, H A ; Comportamento administrativo. Rio de Janeiro: FGV, 1965.

STEINBERG, H; A dimensão humana da governança corporativa: pessoas criam as melhores e piores práticas. São Paulo: Gente, 2003.

VENTURA,L.C. Governança corporativa. A experiência brasileira. In: Palestra proferida na Conferência "Corporate Governance in an international marketplace", promovida pelo Center for International Legal Studies. Salzburg, Áustria, 26 a 28 de junho de 2003.

WONNACOTT, P.; CRUSIUS Y. R. Economia. São Paulo: Mc Graw Hill, 2002

\section{Dados completos dos autores}

\section{Nome Completo: Mario Domingues Ferreira}

Filiação Institucional: UFF Universidade Federal Fluminense - LATEC Laboratório de Tecnologia, Gestão de Negócios \& Meio Ambiente.

Departamento: DEPARTAMENTO DE ENGENHARIA CIVIL.

Função: ex-aluno do Mestrado em Sistema de Gestão.

Endereço: Rua Cel. Moreira César, 168 apt $^{\circ} 404$ Icaraí - Niterói (RJ) CEP 24.230-062 Telefones: (21) 8127-0405; (21) 2611-0370

e-mail:mariodomingues@hotmail.com 
Nome Completo: Osvaldo Luiz Gonçalves Quelhas.

Filiação Institucional: UFF Universidade Federal Fluminense - LATEC Laboratório de Tecnologia, Gestão de Negócios \& Meio Ambiente.

Departamento: DEPARTAMENTO DE ENGENHARIA CIVIL.

Função: PROFESSOR ADJUNTO; COORDENADOR DO LATEC - Laboratório de Tecnologia, Gestão de Negócios \& Meio Ambiente.

Endereço: Rua Passo da Pátria, 156 sala 329 Bloco E - Escola de Engenharia da UFF - bairro S.

Domingos - Niterói (RJ) - CEP 24.210-240

Telefones: (21) 2629-5617; (21) 2717-6390

e-mail:quelhas@latec.uff.com.br

Recebido para publicação em: 21/08/07

Aceito para publicação em: 05/09/07 